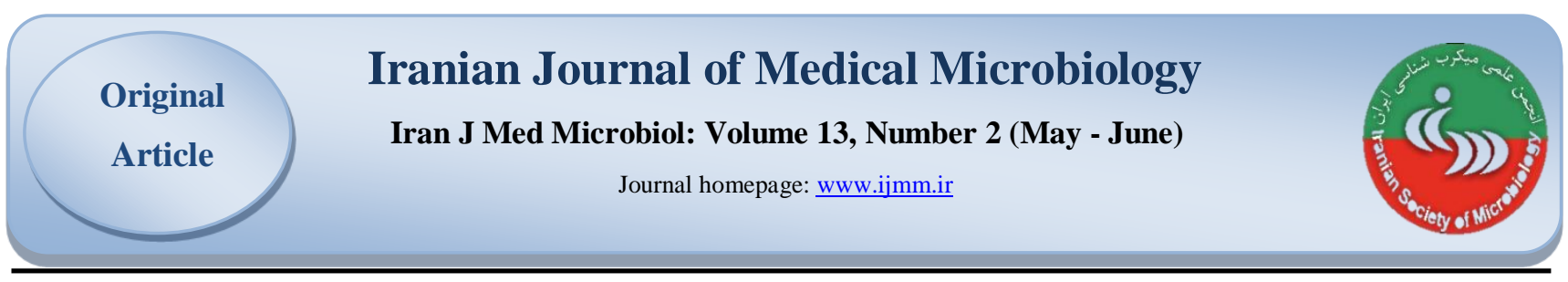

\title{
Investigation of MexAB-OprM efflux pump gene expression in clinical isolates of pseudomonas aeruginosa isolated from Intensive Care Unit
}

\author{
Masomeh Beig', Mohammad Reza Arabestani2 ${ }^{2 *}$ \\ 1- Department of Microbiology, School of Medicine, Hamadan University of Medical Sciences, Hamadan, Iran \\ 2- Brucellosis Research Center, Hamadan University of Medical Sciences, Hamadan, Iran
}

\section{Article Information}

\section{Article Subject: \\ Molecular Microbiology}

DOI:

\section{Corresponding author:}

Mohammad Reza Arabestani, Brucellosis Research Center, Hamadan University of Medical Sciences, Hamadan, Iran

Email:

mohammad.arabestani@gmail.com

Use your device to scan and read the article online

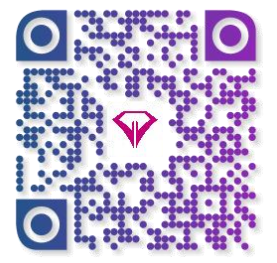

\section{Abstract}

Background and Aims: Pseudomonas aeruginosa is one of the most important pathogens of nosocomial infections, especially in the ICU (Intensive Care Unit), which has resistance to a wide range of antibiotics, especially Carbapenems. Among the most important resistance mechanisms of this bacteria against carbapenems are MexABOprM efflux pump. Therefore, the aim of this study was to evaluate the gene expression of MexAB-OprM efflux pump in clinical isolates of $P$. aeruginosa that isolated from ICU.

Materials and Methods: A total of 33 sampales were isolated from patient in ICU units from different Hamadan hospitals, since november 2018 to May 2019. Antibiotic susceptibility testing was performed using disk diffusion and Minimal Inhibitory Concentration (MIC) methods by Etest for imipenem. Expression levels of MexABOprM efflux pump genes were measured by Real-Time PCR.

Results: The results of statistical analysis showed that the highest resistance was to Ceftriaxone $21(63.63 \%)$ and the lowest resistance was to piperacillin, 11 (33.33\%). The results of the MIC of imipenem showed that among off 33 samples isolated from the ICU, $14(42.42 \%)$ and $19(57.57 \%)$ isolates were resistant and susceptible, respectively. Increased expression of of MexA, MexB and OprM genes compared with control strain were observed in 20\% (4/20), 25\% (5/20) and 20\% (4/20) of isolates, respectively.

Conclusion: Increased expression of MexAB-OprM efflux pump is one of the most common mechanisms in the resistance of $P$. aeruginosa isolates against Carbapenem antibiotics in different units of hospitals especially intensive care unit. So identification of resistance mechanisms to Carbapenem antibiotics can be useful in controlling and treating such resistant isolates.

Keywords: Pseudomonas aeruginosa, Real-TimePCR, PCR, MexAB-OprM

How to cite this article:

Beig M, Arabestani M R. Investigation of MexAB-OprM efflux pump gene expression in clinical isolates of pseudomonas aeruginosa isolated from Intensive Care Unit. Iran J Med Microbiol. 2019; 13 (2) :142-150 


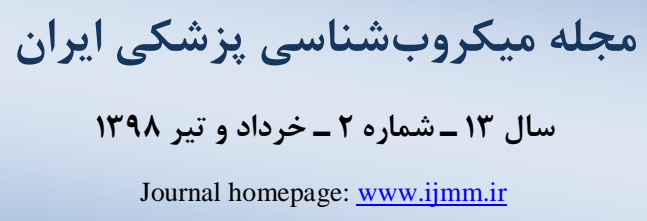

\section{بررسى سطح بيان افلاكس يمب MexAB-OprM در ايزوله هاى بالينى سودوموناس آئروزينوزا جدا شده از بخش مراقبتهاى ويزه}

معصومه بيگ'، محمد رضا عربستانى *r، 1

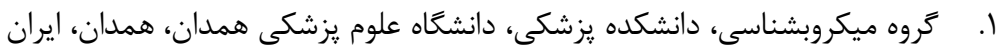

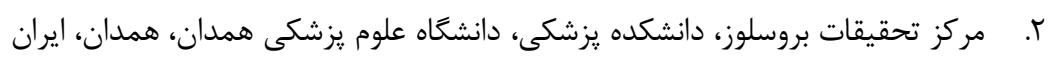

\section{جكيده}

زمينه و هدف: سودوموناس آئروزينوزا از جمله عوامل مههم عفونتهاى بيمارستانى به ويزه در بخش مراقبتهاى ويزه

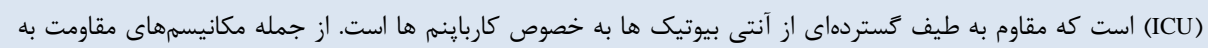

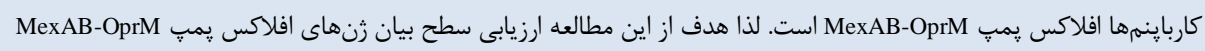

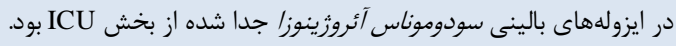

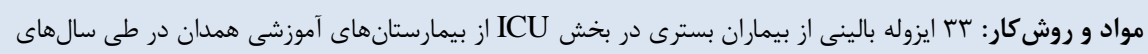

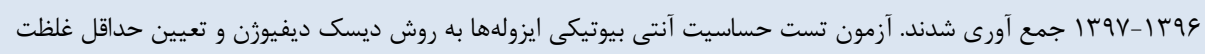

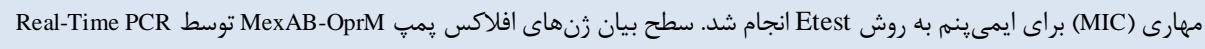

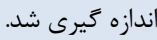

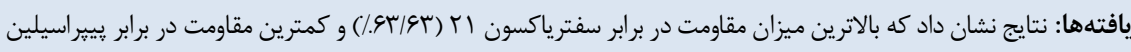

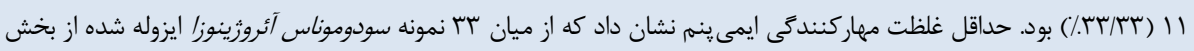

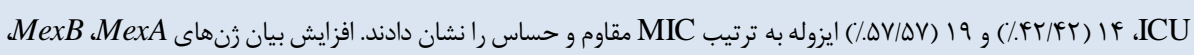
OprM

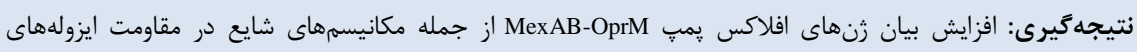

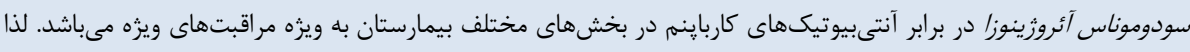

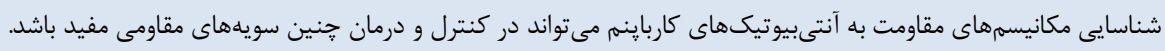
كلمات كليدى: سودوموناس آثروزينوزا, Real-TimePCR, PCR, MexAB-OprM
اطلاعات مقاله

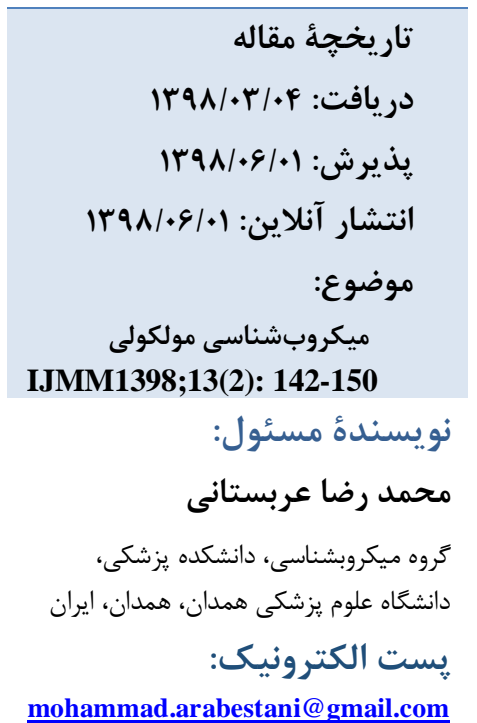

mohammad.arabestani@gmail.com

كجىايت (؟ مجله ميكروبشناسى بزشكى ايران: دسترسى آزاد؛ كبى بردارى، توزيع و نشر براى استفاده غيرتجارى با ذكر منبع آزاد است.

مقدمه

براى ابتلاء به عفونت، نامساعد بودن شرايط بيماران، بسترى شدن

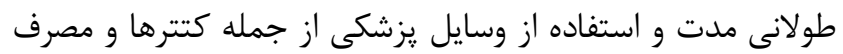
آنتىبيوتيكهاى وسيعالطيف در بيماران بسترى در اين بخشها

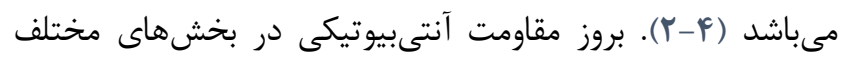

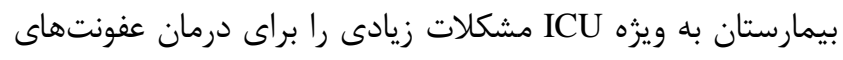

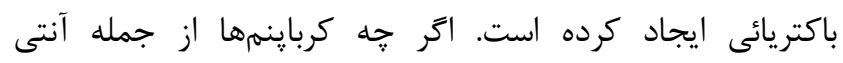
بيوتيكهاى مؤثر براى درمان عفونتهاى سودوموناس آئروزينوزا

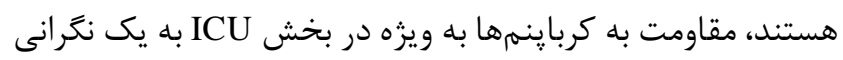
در سراسر جهان تبديل شده است كه موجب افزايش ميزان مرى
سودوموناس آتروزينوزا باكترى گرم منفى و گاتوزن فرصتطلب است كه در سالهاى اخير به عنوان يكى از مهمترين ياتوزنهاى بهري عفونتهاى بيمارستان شناخته شده است. اين باكترى توانائى ايجاد طيف وسيعى از بيمارىها از جمله عفونتهاى مجارى ادرارى، سيستم

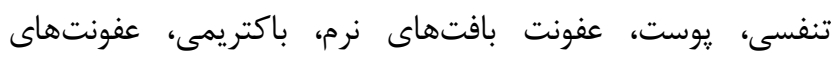

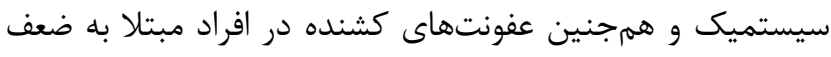
سيستم ايمنى و افراد سرطانى دارد (1). اين باكترى دومين عامل

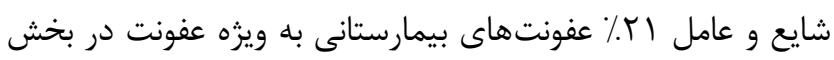

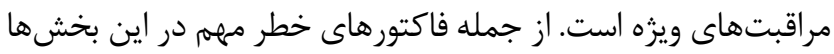


براى تأييد ايزولههاى سودوموناس آئروزينوزا PCR براى زن acsA

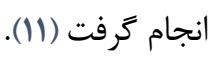

\section{تست حساسيت آنتىبيوتيكى}

مقاومت آنتىبيوتيكى ايزولههاى سودوموناس آنيكي آئروزينوزا، به ديه

روش استاندارد ديسك ديفيوزن و مطابق با روش (CLSI 2018) Laboratory Standards Institute ديسكهاى آنتىبيوتيكى از شركت MAST انكلستان خريدارى شدند

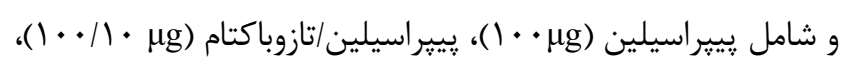

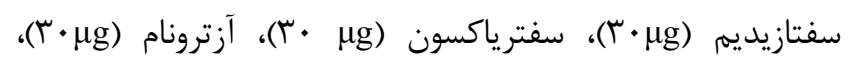

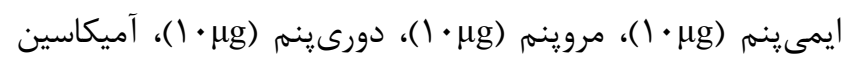

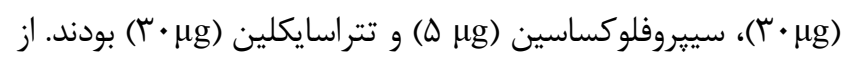
سودوموناس آئروزينوزا 27853 ATCC به عنوان سويه

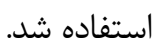

تعيين حداقل غلظت مهارى (MIC) ايمى ينه:

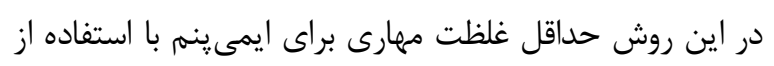

نوار E-test (شركت MAST انغلستان) انجام شد (بر) آ).

\section{استخراج زنوم و انجام روش}

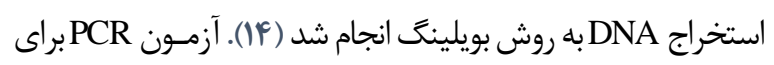

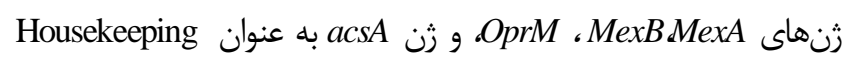

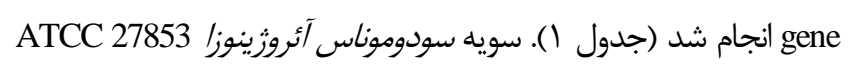

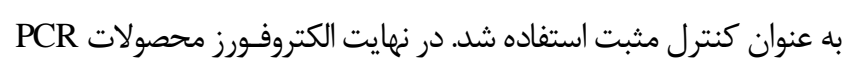

$$
\begin{aligned}
& \text { بـر روى زل آخـارز ا درصـد انجام شد (هان. } \\
& \text { انتخاب ايزولهها: }
\end{aligned}
$$

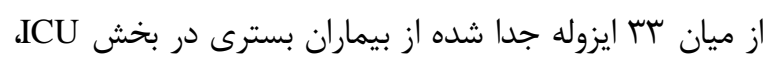

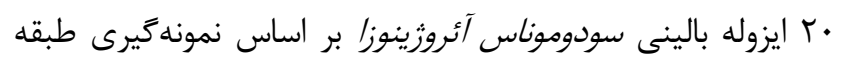

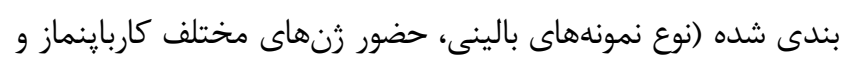

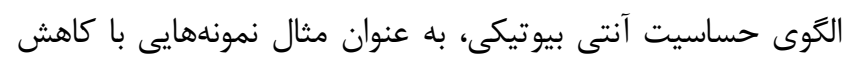

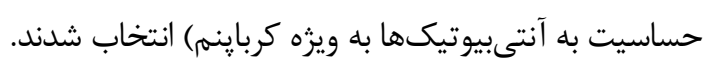

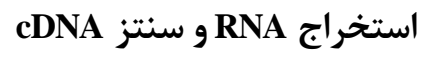

استخراج RNA با استفاده از كيت استخراج RNA استخ

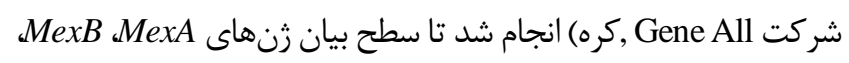

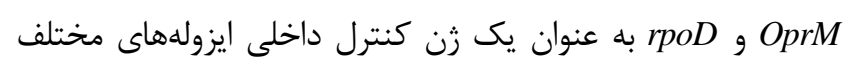

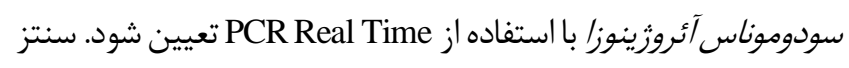

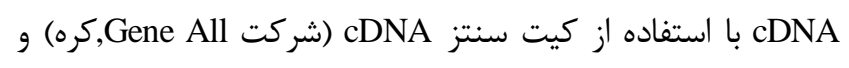

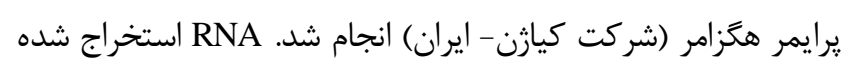

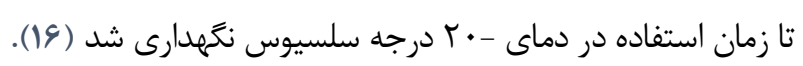

و مير در اين بخش مىشود (ه) . به طور كلى مقاومت سودوموناس

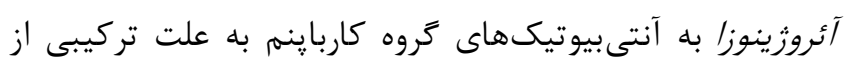

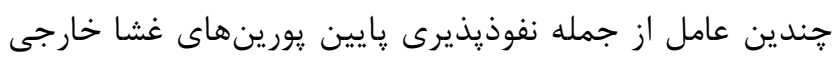

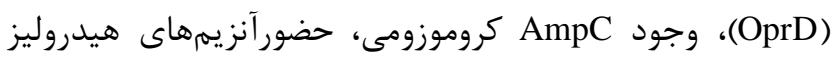

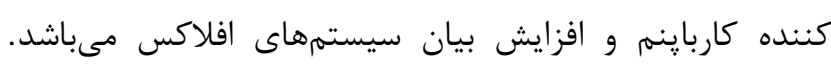

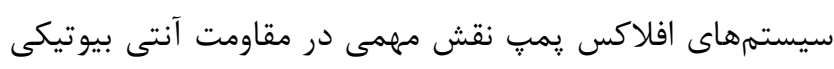

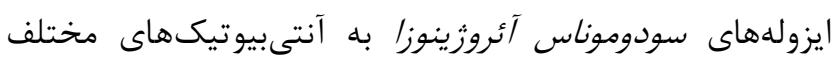

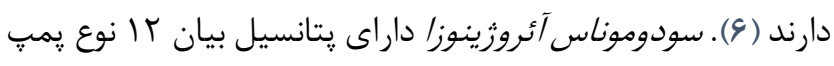

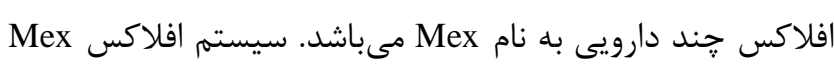

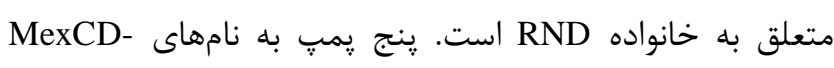
MexXY-OprM ،MexJK-OprM ،MexAB-OprM،oprj مهمرترين پِمٍ هاى افلاكس اين خانواده هستند MexEF-oprN

MexAB-OprM

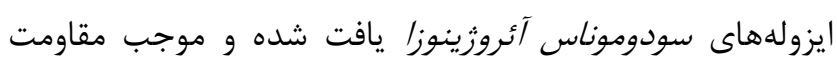

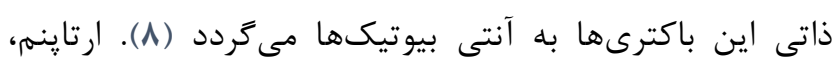

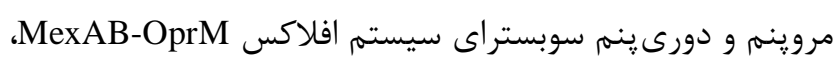

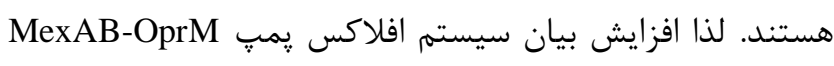

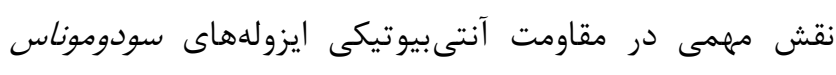

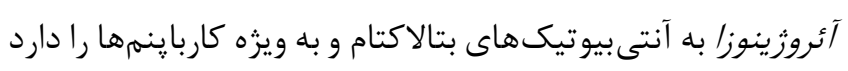

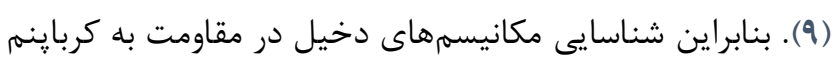

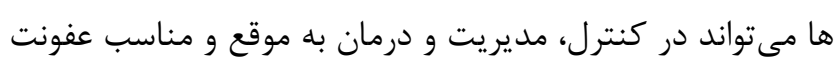

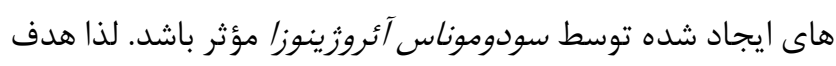

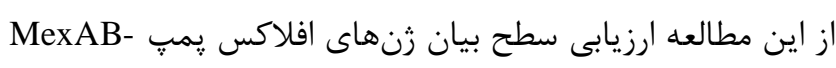

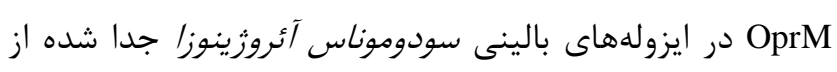

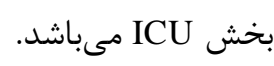

\section{مواد و روش ها}

\section{جداسازى و شناسايى ايزولههاى سودوموناس آئروزينوزا}

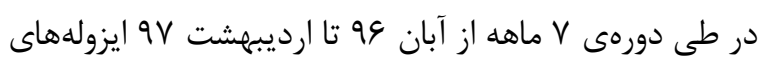

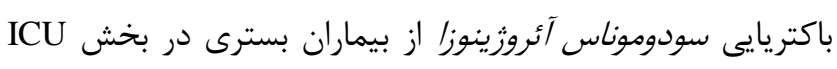

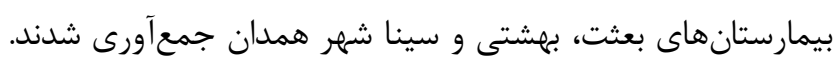

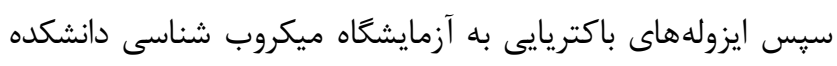

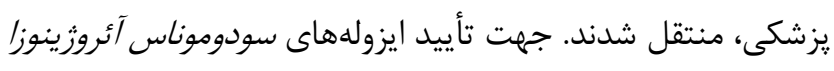

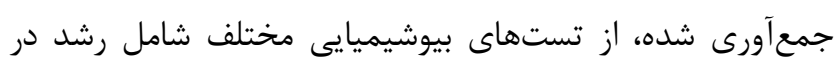

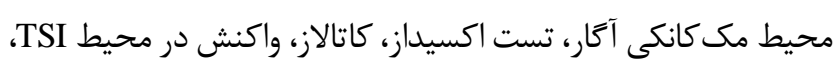

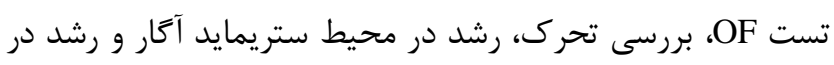

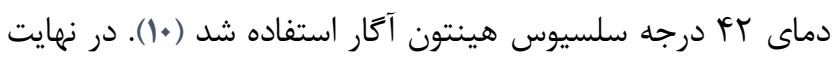




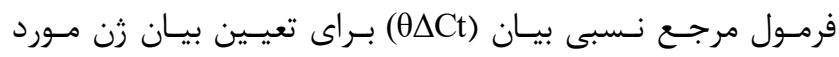
نظـر استفاده كرديــ (IV) (IV).

$$
\text { آناليز آمارى }
$$

آزمون آمارى One way ANOVA بـراى مقايـسه تفــاوت

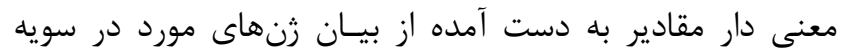

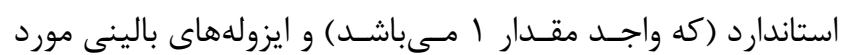

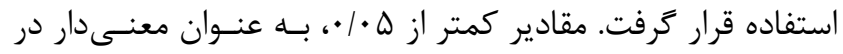

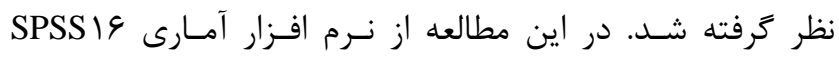

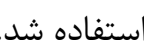

Real- بر رسى سطح بيان زنهاى مورد مطالعه با استفاده از

Time PCR به منظور برسى كمى بيان، زنهاى OprD MexB MexA

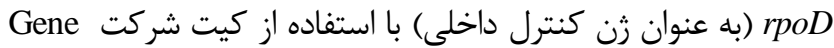
All، كره و يرايمرهاى ذكر شده در جدول إنجام اندام شد. مطابق يروتكـل،

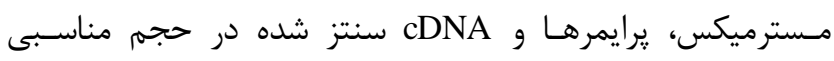
مخلوط شـده و توسط دستخكاه Real-time PCR واكنش انجام

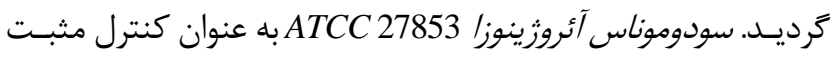
مـورد استفاده قرار كرفت. بيـان زنهاى OprM MexB MexA

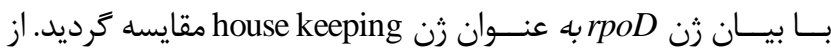
جدول | يرايمرهاى مورد استفاده در RCR Real- Time PCR

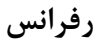

(IA)

(IV)

(19)

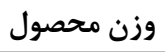

$\Delta \cdot r$

r人.

TFV
توالى برايمر AACCCGAACAACGAGCTG ATGGCCTTCTGCTTGACG TGTCGAAGTTTTTCATTGAG AAGGTCAC GGTGATGGT GATCCCCGACTACCAGCGCCCCG ATGCGGTACTGCGCCCGGAAGGC GGGCTGTCTCGAATACGTTGA ACCTGCCGGAGGATATTTCC ACCTGGTGTACGCCTCGCTGAC GACATAGATGCCCTGCCCCTTGAT

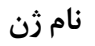

\section{$\operatorname{MexA}$}

MexB

OprM

rpoD

acsA
ATr
الكوى حساسيت ضد ميكروبى ايزولهها: نتايج آزمايشهاى

حساسيت ضد ميكروبى نشان داد كه بالاترين مقاومت به سفترياكسون

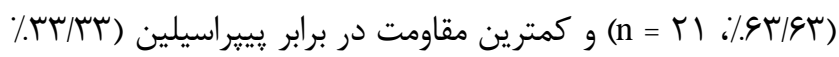

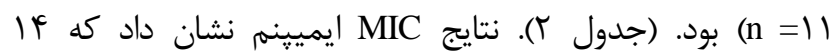

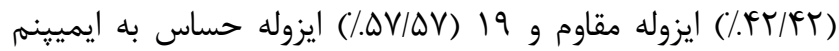

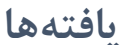

\section{جمع آورى ايزولههاى بالينى}

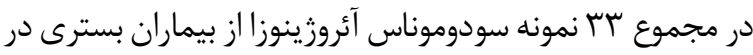

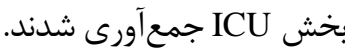

جدول r. نتايج تست حساسيت آنتىبيوتيكى به روش ديسك ديفيورن

\begin{tabular}{|c|c|c|c|}
\hline حساس (درصد) & حدواسط (درصد) & مقاوم (درصد) & آنتى بيوتيك \\
\hline$(F \Delta / F \Delta) \mid Q$ & $(r \mid / r I) V$ & (Tr/rr) 11 & بيبراسيلين \\
\hline$(\Delta \mid / \Delta I) \mid V$ & $(9 / \cdot 9) r$ & (एq/ץq) & يِييراسيلين-تازوباكتام \\
\hline$\left({ }^{F} \Delta / F^{*} \Delta\right) \backslash \Delta$ & $(9 / \cdot 9) r$ & $\left(\mathcal{F} \Delta / \mathcal{F}^{\mathcal{Q}} \Delta\right) \backslash \Delta$ & سفتازيديم \\
\hline$(\Delta F / \Delta F) \backslash \Lambda$ & $(\cdot)$. & $\left(F^{\mp} \Delta / F^{F} \Delta\right) \backslash \Delta$ & ايمىينم \\
\hline$(r \cdot / r \cdot))$. & $(\mid N / / \Lambda)^{9}$ & $(\Delta I / \Delta I) I V$ & 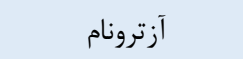 \\
\hline$(\Delta I / \Delta I) \mid V$ & $(\mid r / T)^{F}$ & r| & آميكاسين \\
\hline$(F T / F T) \mid F$ & $(\cdot)$. & $(\Delta V / \Delta V) \backslash 9$ & سييروفلوكساسين \\
\hline$(9 \cdot 19) r$. & $(\cdot) \cdot$ & r & مروينم \\
\hline$(\Delta V / \Delta V) 19$ & $(\cdot) \cdot$ & $(F T / E T) \mid F$ & دورىينهم \\
\hline$(F \Delta / F \Delta) \backslash \Delta$ & $(91.9) r$ & 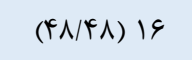 & تتراسايكلين \\
\hline$(\mid N / 1 \Lambda)^{9}$ & $(\mid N / / \Lambda)^{9}$ & $(\varepsilon \Gamma / g T) Y I$ & سفتر ياكسون \\
\hline
\end{tabular}




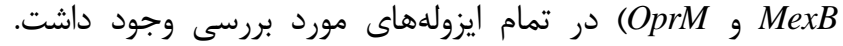

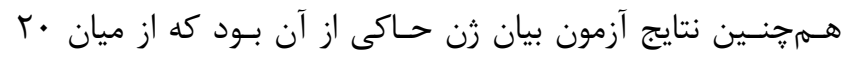

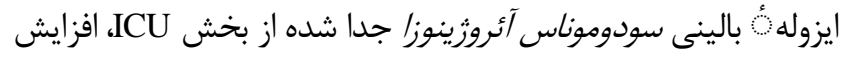

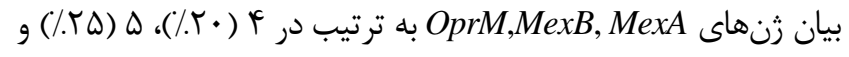

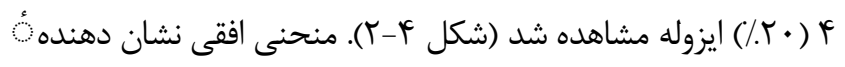

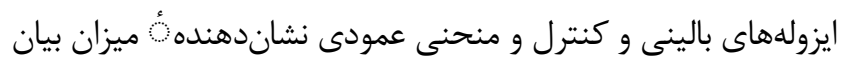

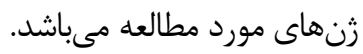

\section{نتايج آزمون PRT-PCR و PCR}

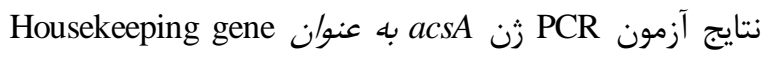

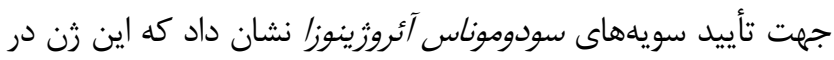
تمامى ايزولههاى هاى باكترى سودوموناس آئروزينوزا وجود دارد (شكل

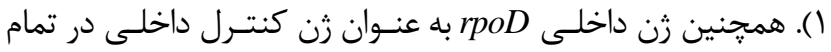

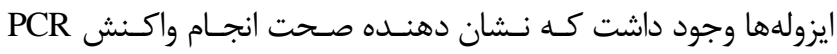

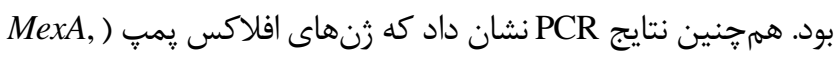

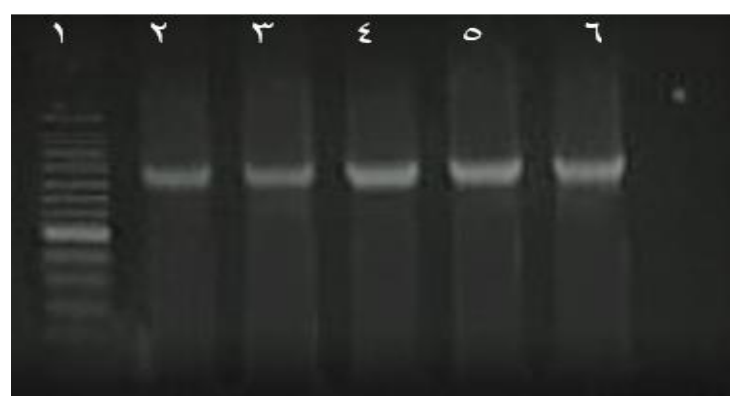

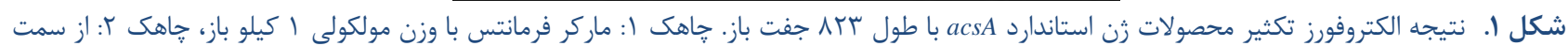

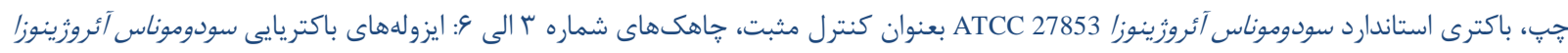

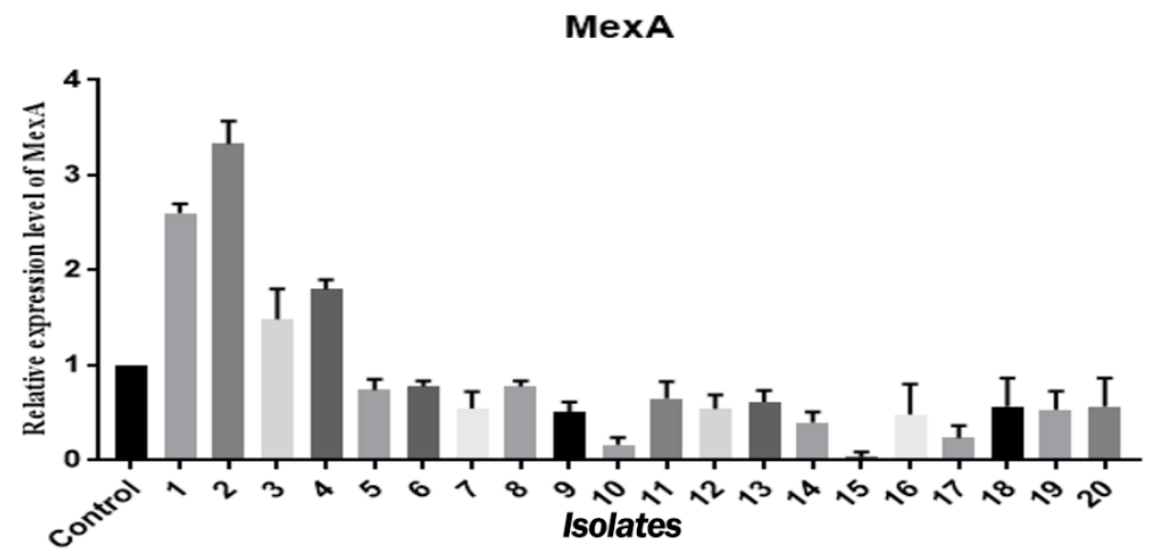

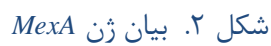

MexB

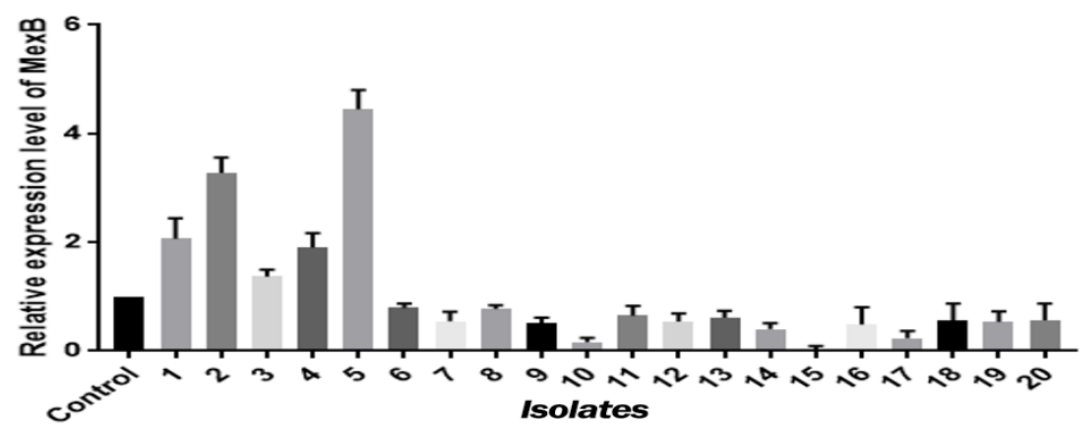




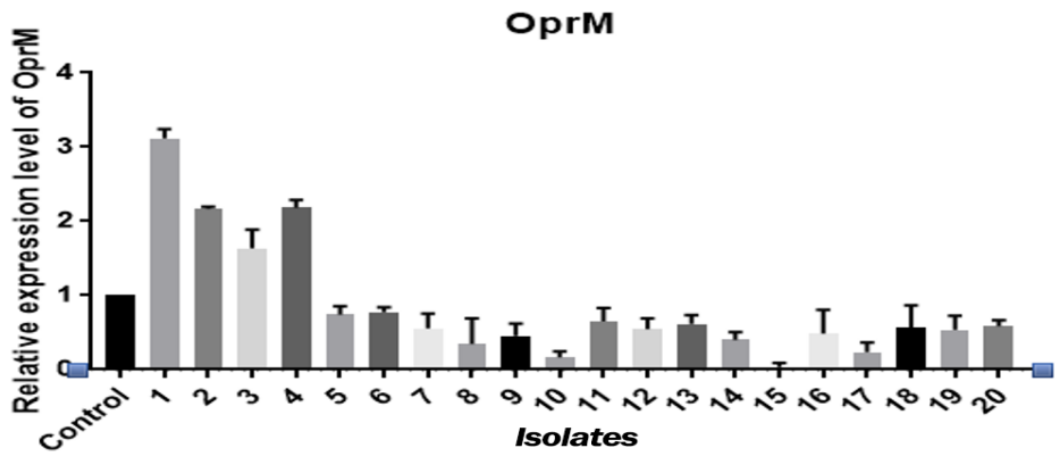

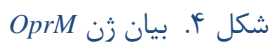

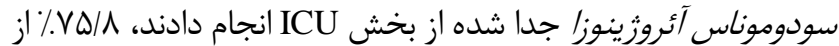

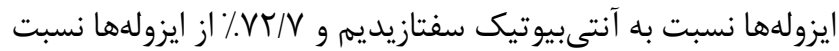
به بِييراسيلين مقاومت داشتند (YN) كه ميزان مقاومت در مطالعه ما نسبت به آنتىبيوتيكهاى فوق كمتر از مطالعه فاضلى بود كه به

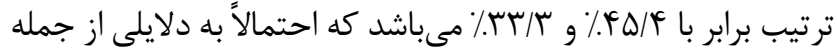
محدوديت در تعداد نمونههاى مطالعه حاضر بود. در مطالعهاى كه

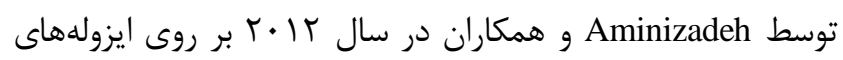
سودوموناس آئروزينوزا جدا شده از بخش ICU انجام شد بيشترين و كمترين ميزان مقاومت به ترتيب نسبت به سفتازيديم (/.AV) و

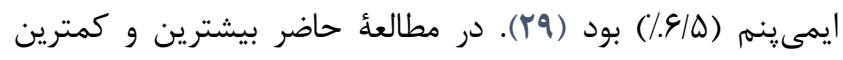
ميزان مقاومت به ترتيب نسبت به آنتىبيوتيكهاى سفترياكسون و وداض

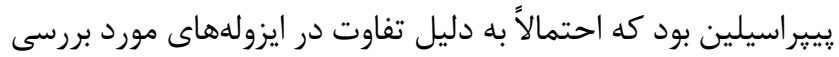
دو مطالعه مىباشد كه الكوى مقاومت متفاوتى دارند. در مطالعه Bayani سودوموناس آئروزينوز/ جدا شده از بخش ICU انجام شد بشترين مقاومت نسبت به آميىسيلين و آميىسيلين-سولباكتام (ب/شهاه/)

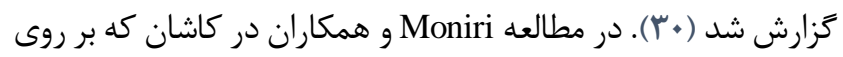
99 ايزوله سودوموناس آئروزينوز/ جدا شده از بخش ICU انجام شد الند

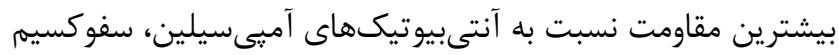

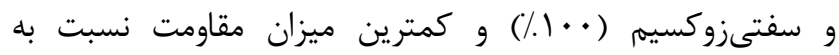

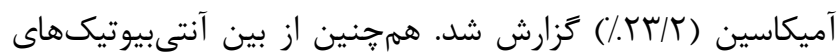

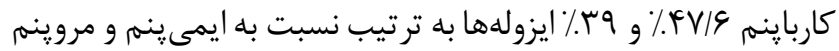
مقاوم بودند (اس) كه مقاومت نسبت به آنتىبيوتيكهاى ايمى ينهم و

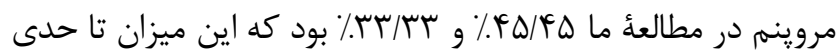
مشابه با مطالعهُ فوق بود كه احتمالاً به اين دليل باشد كه ايزولهها از براز بخش ICU بوده و داراى الكَوى مقاومت مشابهى مى باشند.
بحث

سودوموناس آثروزينوزا از جمله ياتوزنهاى مهم در عفونتهاى بيمارستانى به ويزه در بخش ICU مى باشد كه به آنتى بيوتيكهاى آنس

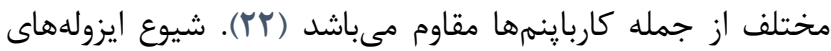

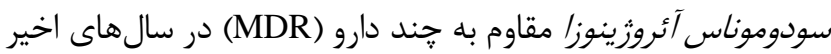

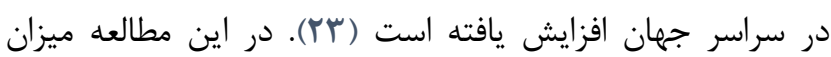
مقاومت نسبت به آنتىبيوتيكهاى ايمى ينهم، مروينهم و دورىينهم به ترتيب Q

Siasi

آنتىبيوتيكهاى كارباينم خط اول درمان براى بيشتر

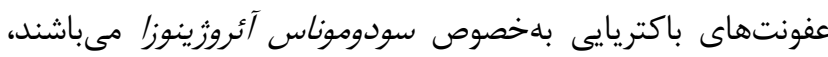

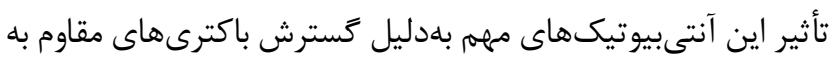

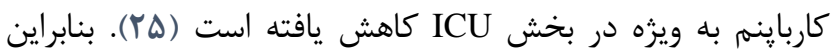
شناسايى سريع و دقيق ايزولههاى سودوموناس آئروزينوزا مقاوم به آنا

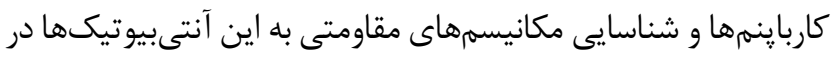
بخش ICU براى درمان مناسب و بيشكيرى از انتشار اين ايزولهها

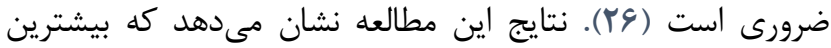

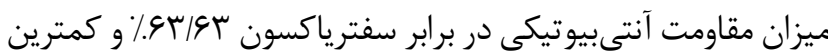

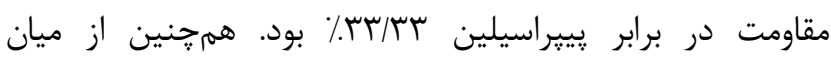
آنتىبيوتيكهاى كارباينه بيشترين مقاومت نسبت به ايمىينم

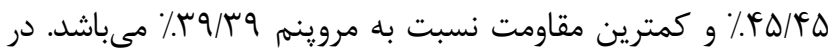
مطالعهاى كه توسط Mihani و همكاران كه بر روى . . إيزولهى بالينى سودوموناس آئروزينوزا در اهواز انجام شد، مقاومت نسبت بـ به

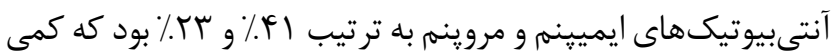

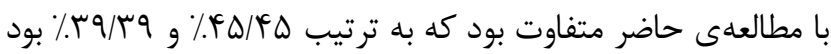
(TV) 


\section{نتيجه گيرى}

نتايج مطالعه حاضر نشان مىدهد كه ايزولههاى سودوموناس آئروزينوزا مقاومت آنتى بيوتيكى بالايى در بخش مراقبتهایى ويثه

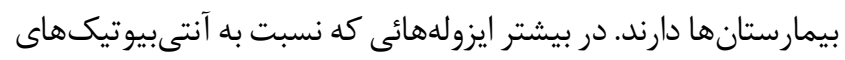
كارباينم مختلف مقاومت داشتند افزايش بيان زنهاى افلاكس يمب MexAB-OprM

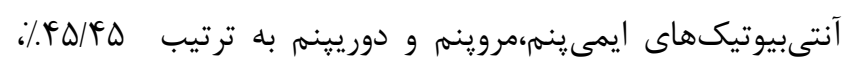

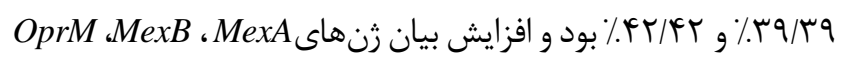

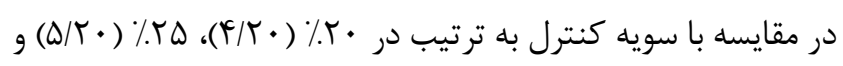

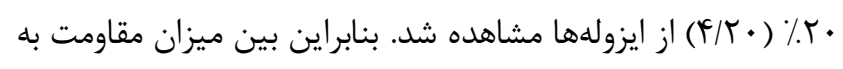
آنتىبيوتيكهاى كارباينم و افزايش بيان سيستم افلاكس پيمب MexAB-OprM در ايجاد مقاومت در بين اين ايزولهها از جمله سيستمهای افلاكس

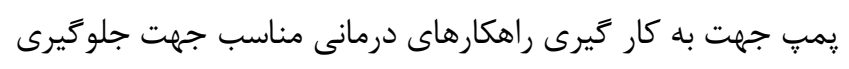
از انتشار جنين سويههاى مقاومى ضرورى به نظر مى بـرسد.

\section{سياسگزارى}

اين مقاله حاصل يايان نامه كارشناسى ارشد با شماره

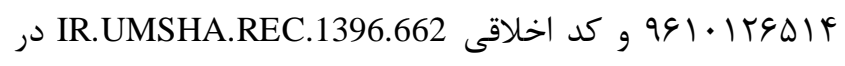

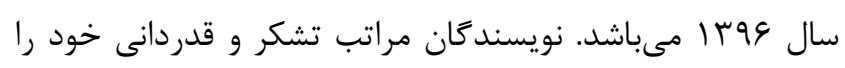
از اين معاونت محترم و يرسنل آزمايشگاه ميكروب شناسى دانشعاه

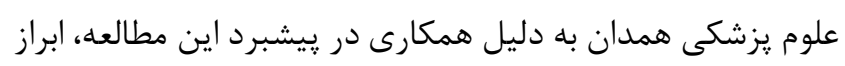

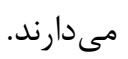

$$
\text { تعارض منافع }
$$$$
\text { بين نويسند }
$$

\section{References}

1. Tam VH, Chang KT, Abdelraouf K, Brioso CG, Ameka M, McCaskey LA, et al. Prevalence, resistant mechanisms, and susceptibility of multidrugresistant bloodstream isolates of Pseudomonas aeruginosa. Antimicrob Agents Chemother 2010; 54(3):1160-4. [DOI:10.1128/AAC.01446-09] [피] [MCID]

2. Bonten MJ, Bergmans DC, Ambergen AW, De Leeuw PW, Van der Geest S, Stobberingh EE, et al Risk factors for pneumonia, and colonization of respiratory tract and stomach in mechanically ventilated ICU patients. Am J Respir Crit Care Med1996; 154(5):1339-46.

[DOI:10.1164/ajrccm.154.5.8912745] [PMID]
افلاكس پمبها به دليل تنوع سوبسترايى در ايجاد مقاومت

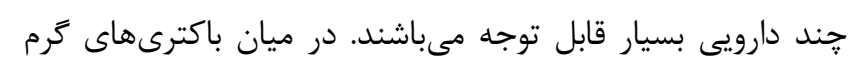

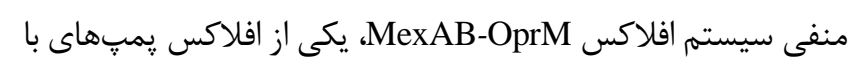
اهميت دخيل در مقاومتهاى جند دارويى سودوموناس آئروزينوزا

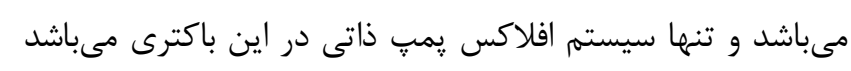

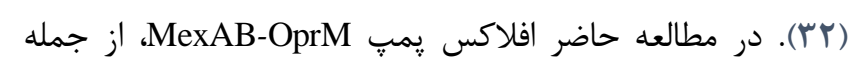

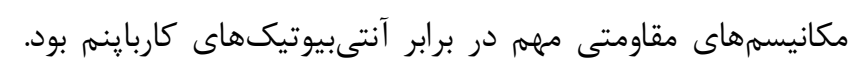

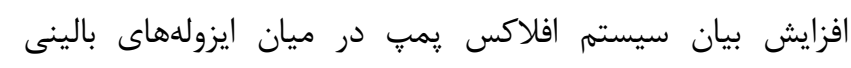

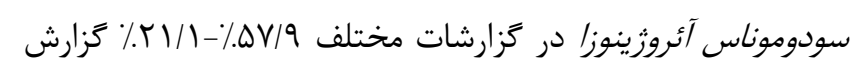

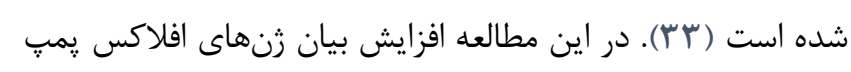
MexAB-OprM انجام شده توسط TubA Moderris و همكارانش در تركيه در سال

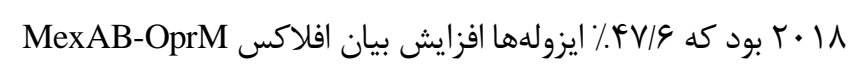

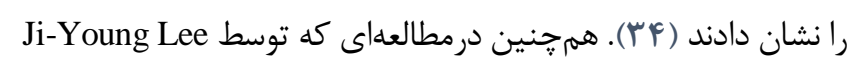

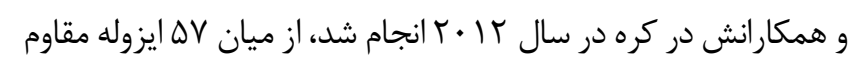

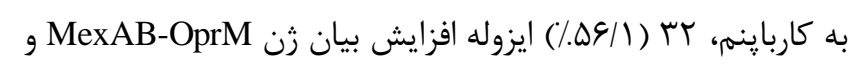

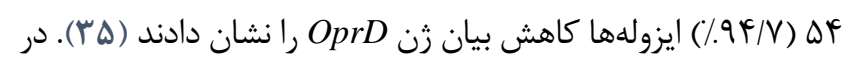
مطالعهُ حاضر، افزايش بيان زنهاى افلاكس ريمب

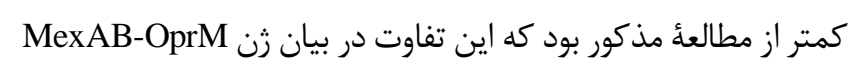

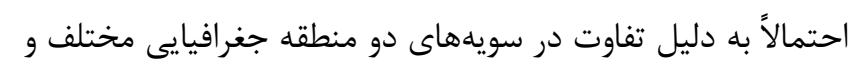

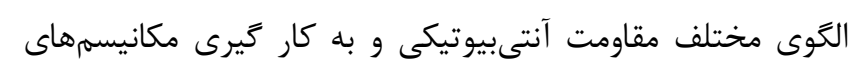
مقاومتى مختلف در ميان سويههاى مختلف است.

3. Agodi Agodi A, Barchitta M, Cipresso R, Giaquinta L, Romeo MA, Denaro C. Pseudomonas aeruginosa carriage, colonization, and infection in ICU patients. Intensive Care Med 2007; 33(7):1155- 61. [DOI:10.1007/s00134-007-0671-6] [PMID]

4. Thuong M, Arvaniti K, Ruimy R, de la Salmonière $\mathrm{P}$, Scanvic-Hameg A, Lucet JC, et al. Epidemiology of Pseudomonas aeruginosa and risk factors for carriage acquisition in an intensive care unit. J Hosp Infect 2003; 53(4):274-82. [DOI:10.1053/jhin.2002.1370] [PMID]

5. Kaye KS, Pogue JMJPTJoHP, Therapy D. Infections caused by resistant gram-negative bacteria: epidemiology and management. Pharmacotherapy 2015;35(10):949-62. [PMID]
[DOI:10.1002/phar.1636] 


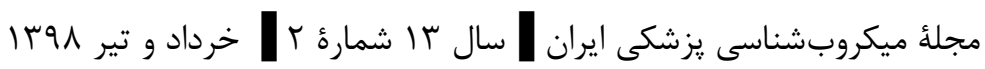

6. Rojo-Bezares B, Cavalié L, Dubois D, Oswald E, Torres C, Sáenz YJJomm. Characterization of carbapenem resistance mechanisms and integrons in Pseudomonas aeruginosa strains from blood samples in a French hospital. J Med Microbiol.2016;65(4):3119. [DOI:10.1099/jmm.0.000225] [PMID]

7. Dreier J, Ruggerone PJFim. Interaction of antibacterial compounds with RND efflux pumps in Pseudomonas aeruginosa. Front Microbiol. 2015;6:660. [DOI:10.3389/fmicb.2015.00660] [PMID] [PMCID]

8. Tian Z-X, Yi X-X, Cho A, O'Gara F, Wang Y-PJPp. CpxR activates MexAB-OprM efflux pump expression and enhances antibiotic resistance in both laboratory and clinical nalB-type isolates of Pseudomonas aeruginosa. PLOS. 2016;12(10):e1005932.

[DOI:10.1371/journal.ppat.1005932]

[PMID] [PMCID]

9. Pan Y-p, Xu Y-h, Wang Z-x, Fang Y-p, Shen J-1JAom. Overexpression of MexAB-OprM efflux pump in carbapenem-resistant Pseudomonas aeruginosa. Arch Microbiol. 2016;198(6):565-71. [DOI:10.1007/s00203-016-1215-7] [PMID]

10. Gaby W, Hadley CJJob. Practical laboratory test for the identification of Pseudomonas aeruginosa.J bacteriol 1957;74(3):356.

11. Annear D, Black J, Govender S. Multilocus sequence typing of carbapenem resistant Pseudomonas aeruginosa isolated from patients presenting at port Elizabeth hospitals, south Africa. Afr J Infect Dis. 2017;11(2):68-74. [DOI:10.21010/ajid.v11i2.9] [PMID] [PMCID]

12. Clinical and Laboratory Standards Institute. 2018. Performance standards for antimicrobial susceptibility testing, 28th ed. CLSI supplement M100S. CLSI, PA. $38-40$.

13. Mustafa $\mathrm{MH}$, Chalhoub $\mathrm{H}$, Denis O, Deplano A, Vergison A, Rodriguez-Villalobos $\mathrm{H}$, et al. Antimicrobial Susceptibility of Pseudomonas aeruginosa Isolated from Cystic Fibrosis Patients in Northern Europe. Antimicrobial agents chemother. 2016;60(11):6735-41 [DOI:10.1128/AAC.01046-16] [PMID] [PMCID]

14. Clarke 1, Millar BC and Moore JC. Extraction of genemic DNA from pseudomonas aeroginosa: a comparison of three methods. Br j Biomed. 2003; 60(1):34-5. [DOI:10.1080/09674845.2003.11978040]

15. Tang Y, Li B, Dai J, Dai J, Wang X, Si J, et al. Genotyping of pseudomonas aeruginosa type III secretion system using magnetic enrichment multiplex polymerase chain reaction and chemiluminescence. $\mathrm{J}$ Biomed Nanotechnol. 2016;12(4):762-9. [DOI:10.1166/jbn.2016.2222] [PMID]
16. Heera R, Sivachandran P, Chinni SV, Mason J, Croft L, Ravichandran M, et al. Efficient extraction of small and large RNAs in bacteria for excellent total RNA sequencing and comprehensive transcriptome analysis. BMC Res Notes. 2015;8(1):754. [DOI:10.1186/s13104-015-1726-3] [PMID] [PMCID]

17. Arabestani MR, Rajabpour M, Yousefi Mashouf R, Alikhani MY, Mousavi SM. Expression of efflux pump MexAB-OprM and OprD of Pseudomonas aeruginosa strains isolated from clinical samples using qRT-PCR. Arch Iran Med. 2015;18(2):102-8.

18. Quale J, Bratu S, Gupta J, Landman D. Interplay of efflux system, ampC, and oprD expression in carbapenem resistance of Pseudomonas aeruginosa clinical isolates. Antimicrob Agents Chemother. 2006;50(5):1633-41. [DOI:10.1128/AAC.50.5.16331641.2006] [PMID] [PMCID]

19. Su F, Wang J. Berberine inhibits the MexXY-OprM efflux pump to reverse imipenem resistance in a clinical carbapenem-resistant Pseudomonas aeruginosa isolate in a planktonic state. Exp Ther Med. 2018;15(1):467-72. [DOI:10.3892/etm.2017.5431]

20. Azimi A, Naserpour T, Bazmi F, Peymani A, Aslanimehr M, Saadat S. Evaluation of oprD Gene Expression in Carbapenem-Resistant Pseudomonas aeruginosa Strains Isolated From Severe Burn Patients With Secondary Infection. Biotech. Health. Sci. 2015. [DOI:10.17795/bhs30748]

21. Gardner JG, Grundy FJ, Henkin TM, EscalanteSemerena JCJJob. Control of acetyl-coenzyme A synthetase (AcsA) activity by acetylation/deacetylation without NAD+ involvement in Bacillus subtilis. ASM. 2006;188(15):5460-8. https://doi.org/10.1128/JB.01181-06 [DOI:10.1128/JB.00215-06] [PMCID]

22. Varaiya A, Kulkarni N, Kulkarni M, Bhalekar P, Dogra JJIJoMR. Incidence of metallo beta lactamase producing Pseudomonas aeruginosa in ICU patients. Indian J Med Res. 2008;127(4). [DOI:10.4103/03774929.41683] [PMID]

23. Plant AJ, Dunn A, Porter RJJEroa-it. Ceftolozanetazobactam resistance induced in vivo during the treatment of MDR Pseudomonas aeruginosa pneumonia. Expert Rev Anti Infect Ther 2018;16(5):367-8.

[DOI:10.1080/14787210.2018.1473079] [PMID]

24. Siasi E, Rafiei Tabatabaii R, MoslehiMehr F. Isolation of bla_vim gene in Antibiotic resistant Pseudomonas aeruginosa from hospitals. New Cellularand Molecular Biotechnology Journal. 2018;8(29):97-106

25. Britt NS, Ritchie DJ, Kollef MH, Burnham C-AD, Durkin MJ, Hampton NB, et al. Importance of site of infection and antibiotic selection in the treatment of carbapenem-resistant Pseudomonas aeruginosa sepsis. 
Antimicrob Agents Chemother. 2018;62(4):e0240017. [DOI:10.1128/AAC.02400-17] [PMID] [PMCID]
Yonsei

Med [DOI:10.3349/ymj.2009.50.3.335] [PMID] [PMCID]

26. Buehrle DJ, Shields RK, Clarke LG, Potoski BA, Clancy CJ, Nguyen MHJAa, et al. Carbapenemresistant Pseudomonas aeruginosa bacteremia: risk factors for mortality and microbiologic treatment failure. J Hosp Infect. 2017;61(1):e01243-16. [DOI:10.1128/AAC.01243-16] [PMID] [PMCID]

27. Mihani F, Khosravi A. Isolation of Pseudomonas aeruginosastrains producing metallo beta lactamases from infections in burned patients and identification of blaIMP and blaVIMgenes by PCR \%J Iranian Journal of Medical Microbiology. 2007;1(1):23-31.

28. Fazeli H, Havaei SA, Solgi H, Shokri D, Motallebirad T. Pattern of Antibiotic Resistance in Pesudomonas Aeruginosa Isolated from Intensive Care Unit, Isfahan, Iran. J Isfahan Med Sch 2013; 31(232): 433-8

29. Aminizadeh Z, Kashi MS. Prevalence of multi-drug resistance and pandrug resistance among multiple gram-negative species: experience in one teaching hospital, Tehran, Iran. Int Res J Microbiol 2011; 2:905.

30. Bayani M, Siadati S, Rajabnia R, Taher AA. Drug Resistance of Pseudomonas aeruginosa and Enterobacter cloacae Isolated from ICU, Babol, Northern Iran. Int J Mol Cell Med 2013; 2(4):204-9.

31. Moniri R, Mosayebi Z, Movahedian AH, Mousavi GA. Emergence of multidrug resistant Pseudomonas aeruginosa isolates in neonatal septicemia. J Infect Dis Antimicrob Agents 2005; 22:39-44.

32. Papadopoulos CJ, Carson CF, Chang BJ, Riley TV. Role of the MexAB-OprM efflux pump of Pseudomonas aeruginosa in tolerance to tea tree (Melaleuca alternifolia) oil and its monoterpene components terpinen-4-ol, 1,8-cineole, and alphaterpineol. Appl Environ Microbiol. 2008;74(6):19325. [DOI:10.1128/AEM.02334-07] [PMID] [PMCID]

33. Amin NE, Giske CG, Jalal S, Keijser B, Kronvall G, Wretlind BJA. Carbapenem resistance mechanisms in Pseudomonas aeruginosa: alterations of porin OprD and efflux proteins do not fully explain resistance patterns observed in clinical isolates. APMIS. 2005;113(3):187-96.

[DOI:10.1111/j.16000463.2005.apm1130306.x] [PMID]

34. Muderris T, Durmaz R, Ozdem B, Dal T, Unaldı O, Aydogan $\mathrm{S}$, et al. Role of efflux pump and OprD porin expression in carbapenem resistance of Pseudomonas aeruginosa clinical isolates. JIDC. 2018;12(01):001-8. [DOI:10.3855/jidc.9486]

35. Lee K, Park AJ, Kim MY, Lee HJ, Cho J-H, Kang JO, et al. Metallo- $\beta$-lactamase-producing Pseudomonas spp. in Korea: high prevalence of isolates with VIM-2 type and emergence of isolates with IMP-1 type. 